\title{
SPATIAL EFFECT AND INFLUENCING FACTORS OF AGRICULTURAL WATER ENVIRONMENTAL EFFICIENCY IN CHINA
}

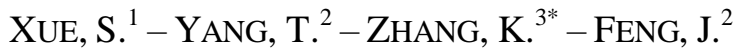 \\ ${ }^{1}$ Business School, Hohai University \\ No. 8 West Focheng Road, 211100 Nanjing, Jiangsu, China \\ (phone: +86-25-5809-9622; fax: +86-25-5809-9213) \\ ${ }^{2}$ Jiangsu Provincial Collaborative Innovation Center of World Water Valley and Water \\ Ecological Civilization, 211100 Nanjing, Jiangsu, China \\ ${ }^{3}$ Institute of Project Management, Hohai University \\ No. 8 West Focheng Road, 211100 Nanjing, Jiangsu, China \\ *Corresponding author \\ e-mail:xuer2399@hhu.edu.cn; +86-25-5809-9628; fax: +86-25-5809-9213 \\ (Received $12^{\text {th }}$ Apr 2018; accepted $27^{\text {th }}$ Jun 2018)
}

\begin{abstract}
Within measurement model from the perspective of strong disposability, the paper measures the Chinese agricultural water environmental efficiency in 2013, by using the spatial econometric model to analyze spatial effect and influencing factors of agricultural water environmental efficiency in China. The results showed that: (1) Agricultural water environmental efficiency of thirty-one provinces in China is spatially correlated, and its distribution characteristics are: on the one hand, agricultural water environmental efficiency is unevenly distributed in space, which characteristics that gradually reduces from east to west; on the other hand, agricultural water environmental efficiency varies in regions, characteristics - the eastern coastal region is high-value agglomeration area, and the central and western regions are low-value agglomeration areas. (2) Agricultural water environmental efficiency can be influenced by many factors, such as high development level of the rural economy, reasonable changes of agricultural structure, good agricultural environment infrastructure, pertinence environmental regulation. However, the extensive mode of rural industrial growth has reduced agricultural water environmental efficiency.
\end{abstract}

Keywords: water pollution, directional distance function, spatial autocorrelation, strong disposability, spatial econometric model

\section{Introduction}

"UN-Water Global Analysis and Assessment of Sanitation and Drinking-Water (GLAAS) 2017 report" points out that nearly 2 billion people around the world are still using faecal contaminated sources of drinking water and are therefore at risk of contracting cholera, dysentery, typhoid and polio. It is estimated that contaminated drinking water causes more than 500,000 deaths per year due to diarrhoea. With the rapid development of rural economy, the problems of agricultural water environment in China gradually appear. "China's environmental state bulletin in 2014" shows that agricultural ammonia and nitrogen emissions accounted for $31.4 \%$ of total emissions in the national wastewater discharge in 2014, while agriculture chemical oxygen demand (COD) emission accounted for $48 \%$. In order to control the environmental pollution of rural water, the relevant laws, regulations and policies of the central government and the local government all involve issues relating to rural water environmental governance. 
The initial stage of rural water environment management is mainly focused on the formulation of relevant standards and the implementation of regulatory responsibilities. With the continuous intensification of rural water pollution, the source governance strategy that integrates environmental protection policies with industrial policies has been proposed. Due to the randomness and decentralization of rural non-point source pollution, comprehensive environmental supervision is difficult to achieve. It is also more difficult for farmers and township enterprises to afford taxes and penalties for water pollution. Therefore, more effective governance measures are to strengthen publicity, education, and guidance so that farmers can understand the damages of water environmental pollution, master clean production technologies, and participate in water environment management. On the one hand, the rapid growth in the number of policies reflects the increasing importance of our country's water environment issues. On the other hand, policy measures have been constantly changing from "command control type" to "voluntary participation type"; policy objectives have also gradually changed from macroscopic guidance to microcosmic operations. To achieve the goal of coordinated development of economic growth and water environmental protection, more and more people pay attention to the improvement of the efficiency of resources and environment. On this basis, many scholars began to study environmental efficiency and proved the existence of spatial agglomeration effect of agricultural water resources in China (Li et al., 2008; Sun and Liu, 2009; Sun et al., 2010). Due to agricultural water pollution along with the rainfall and runoff in space migration, does agricultural water environmental efficiency have the effect of spatial agglomeration as well as agricultural water resources efficiency? What are the factors that influence agricultural water environmental efficiency? Through the study of the question above, the agricultural water environmental efficiency can be better improved. Thus the coordinated development of economy and environment can be ensured. Therefore, many scholars have researched agricultural water environmental improvement from the perspective of environmental efficiency.

\section{Literature review}

For better coordination of economic development and environmental protection, the World Business Council on Sustainable Development (WBCSD) put forward the concept of environmental efficiency to measure the environmental cost during economic development process, and thus to estimate the sustainability of the economy. According to the WBCSD definition, environmental efficiency is achieved through the delivery of "competitively priced goods and services that satisfy human needs and bring quality of life while progressively reducing environmental impacts of goods and resource intensity throughout the entire life-cycle to a level at least in line with the Earth's estimated carrying capacity". Based on this concept, many scholars began to do research in the field of agriculture environment efficiency. Fulginiti et al. (1998) used the Malmquist Production Index and the Cobb-Douglas Production Function to study the agricultural environmental productivity in 25 developing countries over 25 years. The results showed that the production efficiency of the agricultural environment in the least developed countries decreased most significantly to more than half. Countries have experienced a decline in agricultural production efficiency. Regardless of the environment, Ruttan (2002) found that the world's agricultural productivity had dramatically increased in the past half-century. Galanopoulos (2004) used DEA-based 
Malmquist Productivity Index method to evaluate the agricultural environmental efficiency of EU countries and 13 other candidate countries. The results showed that European countries generally have low agricultural environmental efficiency. Nanere et al. (2007) revised the efficiency of agricultural production and considered that the level of environmental damage has a significant impact on the efficiency measurement model. Restuccia et al. (2008) compared agricultural production efficiency and total factor productivity in different countries and regions and found that the correlation between agricultural environmental productivity and labor productivity was not significant in the same period. but compared to agricultural total factor productivity in developed and developing countries, the gap continues to grow. Barnes et al. (2009) believes that measuring the environmental efficiency can achieve a win-win situation, which can not only reduce the investment of farmers but also reduce the environmental externalities. Li (2014), Li et al. (2011) and Min et al. (2012) made an empirical analysis of agricultural environment efficiency of several provinces in China from the perspective of agricultural economic development, resource utilization and environmental coordinated development. Yang and Chen (2011) measured the growth of agricultural environmental technical efficiency of several provinces in China, and the empirical results show that the agricultural environment efficiency in the east is significantly higher than that in the central and western regions. The difference between the central region and the western region is very small. Ignoring environmental factors will overestimate China's agricultural productivity growth. Pan and Ying (2013a) investigated agricultural productivity under the restriction on resources and environment in China. The results show that without consideration of environmental pollution constraints, China's overall agricultural productivity level will be overestimated, and the state of agricultural productivity diversification in each province will continue. Zhang and Feng (2016) studied measurement model of agricultural environment efficiency in China and its dynamic evolution under the strong disposable perspective. The above research on environmental efficiency measurement laid the foundation for follow-up study.

In addition, scholars at home and abroad have further studied the influencing factors of environmental efficiency. Monchuk (2010) studied the influencing factors of agricultural environment efficiency in China. It proved that agricultural structure changes and agricultural economic development level significantly improved the efficiency of the agricultural environment while the industrialization lowered the efficiency of agricultural environment. Through the research on the influencing factors of Spanish agriculture ecological efficiency, Picazo-Tadeo (2011) found out that environmental regulation, education level, and agricultural training can improve the efficiency of agricultural ecological while agricultural economic development level had the opposite effect. According to the study of Gadanakis (2015), the British agricultural technical efficiency was mainly influenced by farm scale, farmers' level of education and experience, agricultural environmental payment, and cost, environmental regulation, etc. Liang et al. (2012) found that agricultural environmental technology efficiency could be better promoted by improving the level of economic development and agricultural infrastructure investment while the agricultural environment management policy affected little on it. Through empirical research, Li (2014) concluded that China's agricultural green productivity was influenced by factors such as the household contract responsibility system, agricultural price system reform, rural industrialization, public agricultural investment, agricultural taxes and fees reform and 
agricultural openness variables, etc. Yang and Liu (2015) found that high abundance of water resource, farmland water conservancy construction and environment regulation could be obviously beneficial to agricultural water resources efficiency.

In conclusion, the existing research has made abundant achievements in measurement and influencing factors of environmental efficiency, which provides a reference for the rural water environment management and relevant policy making. However, the spatial effect of agricultural water environmental efficiency was taken little consideration.

Moreover, the current efficiency measurement model and agricultural water environmental characteristics at present stage have some differences. Therefore, a more reasonable efficiency measurement model should be used to study the spatial heterogeneity of agricultural water environmental efficiency in China, and to analyze the influencing factors of these spatial differences.

\section{Research method}

\section{Efficiency measurement model}

The existing efficiency measurement models are mainly based on foreign agricultural environmental efficiency and the domestic industrial environmental efficiency such as joint weak disposable distance function and the SBM model. However, agricultural water environmental efficiency in China now could not meet the demand for pollution (undesirable outputs) characteristics including null associatively and joint weak disposability. First, in regards to characteristics of agricultural pollution, the agricultural environmental pollution in China at this stage is not inevitable, and the agricultural environmental governance can increase production to some extent. Therefore, it does not meet the requirements for combined weak disposal and zero integration. Second, as for the pollution control costs, agricultural environmental pollution control yields benefits to economy to some degree and does not satisfy the economic significance of the joint weak disposition. Third, from the perspective of environmental regulation, the existing agricultural environmental regulation is not sufficient to achieve the transformation of agricultural environmental pollution from strong disposability to joint weak disposability. Based on the above analysis, the pollution characteristics of China's agricultural environment are different from those of industrial environmental pollution and agricultural pollution in developed countries. The combination of zero-integration and weak disposal is still unsatisfactory. Therefore, another way must be found to measure the agricultural environmental efficiency in China. The strong disposability thought provides a solution for measuring China's agricultural environmental efficiency (Zhang and Feng, 2016). Here is the definition (Eq. 1):

$$
A W E E=\frac{\mathrm{V}}{1+D(x, y, b ; g)}
$$

where $x$ is input variable; $y$ is the expected output variable; $b$ is the unexpected output variable;

$$
D(x, y, b ; g)=\sup \left\{\beta:(y, b)+\beta g \in p^{s}(x)\right\}
$$




$$
p^{s}(x)=\left\{(y, b) \mid \sum_{j=1}^{n} z_{j} x_{j} \leq x, \sum_{j=1}^{n} z_{j} y_{j} \geq y, \sum_{j=1}^{n} z_{j} b_{j} \leq b, z_{j} \geq 0\right\}
$$

\section{Spatial econometric model}

(1) Spatial autocorrelation model

Global Moran's I index describes the cluster state of the distribution of regional economic activities from the whole regional space view. Here is the definition (Eq. 2):

$$
I=\frac{\sum_{i=1}^{n} \sum_{j \neq i}^{n} W_{i j} z_{i} z_{j}}{\sigma^{2} \sum_{i=1}^{n} \sum_{j \neq i}^{n} W_{i j}}
$$

Where $n$ is the number of observations; $X_{i}$ is the observation in position $i$; $Z_{i}$ is the standardized transformation of $X_{i}$;

$$
z_{i}=\frac{x_{i}-\bar{x}}{\sigma}, \bar{x}=\frac{1}{n} \sum_{i=1}^{n} x_{i}, \sigma^{2}=\frac{1}{n} \sum_{i=1}^{n}\left(x_{i}-\bar{x}\right)^{2}
$$

Global Moran's I index involves only the whole regional space, whereas the spatial association patterns of separate regions in the global geographic range are not included. Here we use the local Moran's $I$ index to analyze local characteristics of spatial association. Here is the definition of local Moran's I index (Eq. 3):

$$
I=\frac{I_{i}-E\left(I_{i}\right)}{\sqrt{\operatorname{Var}\left(I_{i}\right)}}
$$

where $I_{i}=\sum_{j=1}^{n} w_{i j}\left(x_{i}-\bar{x}\right)\left(x_{j}-\bar{x}\right)$.

(2) Spatial lag model

Spatial lag model (SLM) is used to study whether the variables have a spillover effect in the space aspect. The mathematical expression of SLM is as follows (Eq. 4):

$$
y=\rho W y+X \beta+\varepsilon
$$

Where $x$ is independent variable; $y$ is dependent variable; $\beta$ reflects the effect of $x$ on $y$; $\rho$ is the spatial autoregressive coefficient; $W y$ is endogenous variable.

(3) Spatial error model

Spatial error model (SEM) can be used to determine whether an error term is dependent on space level. The definition of SEM is as follows (Eq. 5):

$$
\begin{gathered}
y=X \beta+\varepsilon \\
\varepsilon=\lambda W \varepsilon+\mu
\end{gathered}
$$


where $x$ is independent variable; $y$ is dependent variable; $\beta$ reflects the effect of $\mathrm{x}$ on $\mathrm{y} ; \varepsilon$ represents the random error term vector; $\lambda$ is autoregressive parameters; $\mu$ is random error vector of standard normal distribution; $W$ is spatial weight matrix; $\lambda$ stands for the error impact degree which adjacent area has in the local area.

\section{Efficiency measure and its spatial characteristics}

\section{Variable definition and data processing}

After full consideration of the existing research achievements and the characteristics of agricultural water environment (Li et al., 2014; Han, 2013; Pan and Ying, 2013b; Liang et al., 2012), the indexes in this paper are selected as listed in Table 1.

Table 1. Measurement index of agricultural water environmental efficiency

\begin{tabular}{|c|c|c|}
\hline First-grade indexes & Second-grade indexes & Variables interpretation \\
\hline \multirow{5}{*}{ Input } & Land input & Cultivated land area \\
\hline & Irrigation investment & Effective irrigation area \\
\hline & Fertilizer input & $\begin{array}{l}\text { The net amount of fertilizer applied in agricultural } \\
\text { production, including nitrogen, phosphorus, potassium } \\
\text { and compound fertilizer }\end{array}$ \\
\hline & $\begin{array}{l}\text { Agricultural machinery } \\
\text { investment }\end{array}$ & Agricultural machinery total power \\
\hline & Labor input & $\begin{array}{l}\text { Gross labor in agriculture, forestry, animal husbandry } \\
\text { and fishery }\end{array}$ \\
\hline \multirow{4}{*}{ Output } & \multirow[t]{2}{*}{ Expected output } & $\begin{array}{l}\text { Total output value in agriculture, forestry, animal } \\
\text { husbandry and fishery (economic benefit) }\end{array}$ \\
\hline & & Grain yield (social benefit) \\
\hline & \multirow{2}{*}{ Unexpected output } & Emission of COD \\
\hline & & Emission of nitrogen and phosphorus \\
\hline
\end{tabular}

The sources of nitrogen and phosphorus emissions, as well as COD emissions, come from two periods. The first period is after 2012, and the data can be found in "China Environmental Statistics Yearbook". The second period is between 1990 and 2012, and the statistics can be measured by the way of unit investigation and evaluation of related literature (Chen et al., 2006; Lai et al., 2004). The formula is as follows (Eq. 6):

$$
E=\sum_{i} S U_{i} \times \rho_{i} \times L C_{i}
$$

where $E$ is agricultural pollutant emission; $S U_{i}$ is pollutant production base; $\rho_{i}$ is intensity coefficient of pollutants; $L C_{i}$ is pollutant discharge coefficient.

Due to the difficulty of obtaining data on water environmental pollution, the research only uses the data before 2013 for analysis. This study will examine the agricultural water environmental efficiency of 31 provinces in mainland China. Based on China's development and policy factors, these provinces and autonomous regions are divided into three areas: east, central, and west China. The data above are from the annual "China Statistical Yearbook", "China Rural Statistical Yearbook", "Handbook of 
Agricultural Pollution Fertilizer Loss Coefficient" and "Poultry Breeding Industry Pollution Discharge Coefficient Handbook", etc.

\section{Measurement result}

The measurement result of China's agricultural water environmental efficiency in 2013 can be obtained through Equation 1 and Figure 1 is the sub-bitmap. The subbitmap shows that the spatial distribution characteristics of agricultural water environmental efficiency in China is uneven and the distribution pattern can be described to be gradually decreased from east to west. The average efficiency values of eastern, middle and western regions are $0.89,0.80$ and 0.75 .

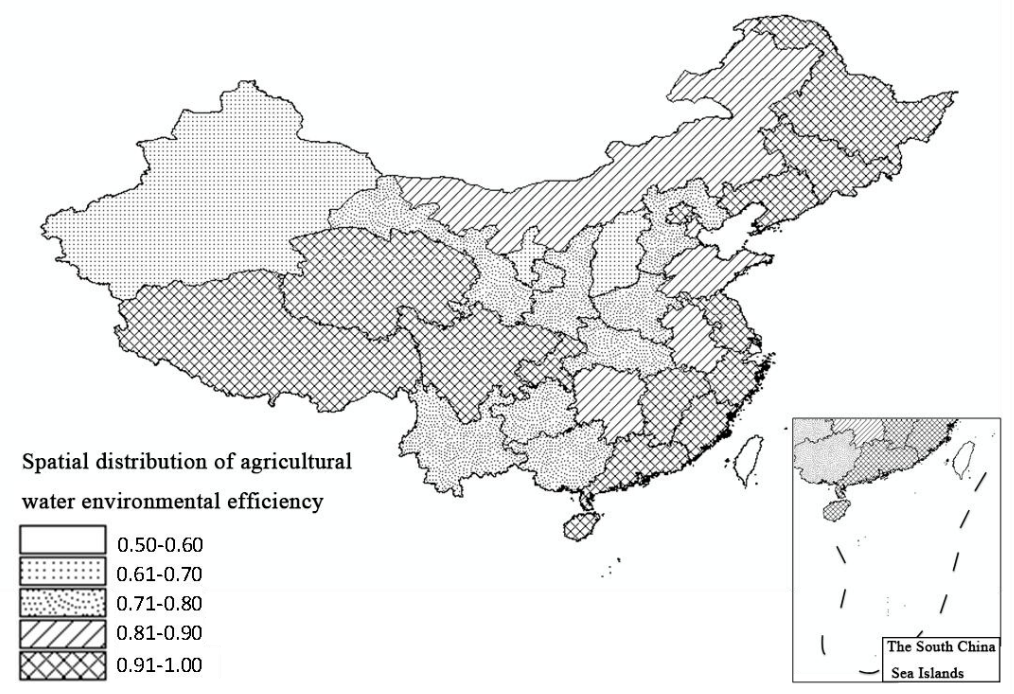

Figure 1. Spatial distribution of agricultural water environmental efficiency

\section{Spatial autocorrelation test}

By using global Moran's I method to test the measurement results of agricultural water environmental efficiency of China in 2013, the research showed that all the results managed to pass the test under 5\% confidence level. The result of this test can support the conclusion that the agricultural water environmental efficiency of thirty-one provinces in China is spatially correlated and its distribution has certain accumulation characteristics, and therefore it is easy to form neighborhood imitation effect of agricultural water environmental efficiency.

To further study the spatial dependence situation of agricultural water environmental efficiency in different regions, the local Moran's $I$ test and Local indicators of spatial association (LISA) was carried out in 2013 (Fig. 2). LISA is used to test whether there is agglomeration in the local area. The LISA agglomeration area reflects the closeness of the observation values in adjacent areas to characterize regional differences. From Figure 2 it turns out that most of the eastern coastal provinces present a High-High accumulation model while some of the mid-western regions still carry a Low-Low accumulation pattern. The former area usually holds high agricultural water environmental efficiency value and is more prone to cooperate with each other to improve that efficiency. The regional economic development level can partly explain 
this phenomenon. The natural characteristics of the more developed river system and more intertwined river network also play an important role. On the contrary, poorer water resources sharing system and a rather slow economic development level have formed a less cooperated environment in the mid-western area, and this has caused low agricultural water environmental efficiency value.

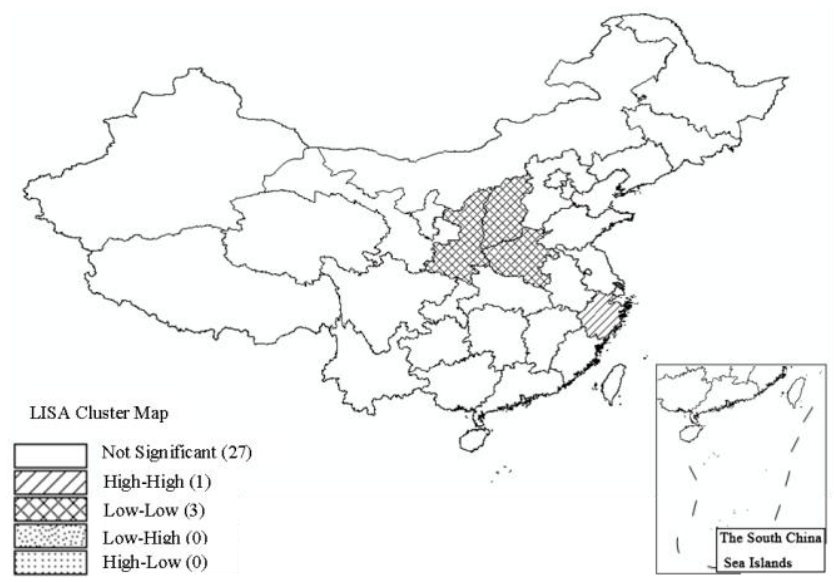

Figure 2. Local spatial auto-correlated LISA cluster map of agricultural water environmental efficiency in China

\section{Analysis of the factors influencing spatial heterogeneity of agricultural water environment}

\section{Variable selection and data sources}

The efficiency of agricultural water environment is influenced by many factors, such as the economy, resources, environment, etc. The influence factors here were chose out of two considerations. The existing research papers listed in Table 2 and the characteristics of agricultural water environment itself. Based on this, the following influence indexes are selected.

(1) Rural Economy Development Level (REDL). This index is based on per capita net income, which defines the year 2000 as the base year, in rural areas to exclude the impact of price change.

(2) Agricultural structure change (ASCP\&ASCG). ASCP represents the proportion of poultry industry output in total agriculture output value, and ASCG shows the proportion of grain crops and economic crops.

(3) Rural industrialization (RI). The total output value of township enterprises which make up the gross rural output value is the measure of this indicator.

(4) Agricultural environmental infrastructure level (AEIL). The investment quota of agricultural infrastructure is the standard.

(5) Environmental regulation (ERCOD\&ERNH). Environmental regulation can be reflected in concrete measures like environmental policy making, environmental law enforcement and environmental governance Investment, etc. Considering this, the indexes measuring environmental regulation could relatively be the quantity of environmental policy, the number of pollution control law enforcement and pollution control costs, etc. However, these indexes have their limitations on both index attributes and data sources which might cause deviant results. Therefore, in this paper, the effect 
of pollutant control is used to measure environmental regulation precisely. For example, Cole and Elliott (2003) used pollutant emission density as an indicator to measure environmental regulation intensity. Changes in pollutant emissions and pollution emission intensity coefficient were respectively used as the indicator by $\mathrm{Fu}$ and $\mathrm{Li}$ (2010) and Li and Tao (2012) to measure environmental regulation better. Based on this idea, agricultural COD and ammonia nitrogen emission intensity were chosen as the proxy variable of environmental regulation in this research. The relationship between environmental regulation strength and pollutant emissions intensity is that the former is directly proportional to the latter.

The data above are drawn from "China Statistical Yearbook", "China Rural Statistical Yearbook" and "China Environmental Statistics Yearbook".

Table 2. Influence factors of representative researches

\begin{tabular}{c|c|c|c}
\hline Author & Year & Research contents & Selection of influence factors \\
\hline Yang Qian & 2015 & $\begin{array}{c}\text { Factors affecting the } \\
\text { efficiency of agricultural water } \\
\text { resources }\end{array}$ & $\begin{array}{c}\text { Agricultural economic development } \\
\text { level; Degree of Water resource } \\
\text { abundance; Construction of water } \\
\text { conservancy works; Water saving } \\
\text { agriculture development level, Planting } \\
\text { structure; Environmental regulation }\end{array}$ \\
\hline Li Gucheng & 2014 & $\begin{array}{c}\text { Analysis of the institutional } \\
\text { factors of the growth of green } \\
\text { agricultural productivity }\end{array}$ & $\begin{array}{c}\text { Environmental regulation } \\
\text { Factors affecting the } \\
\text { agricultural environmental } \\
\text { technology efficiency }\end{array}$ \\
Picazo-Tadeo & 2012 & $\begin{array}{c}\text { Agricultural structure; Regional } \\
\text { economic development level; } \\
\text { degree; Agricultural infrastructure } \\
\text { conditions; Environmental regulation }\end{array}$ \\
\hline Monchuk & 2010 & $\begin{array}{c}\text { Agricultural ecological benefit } \\
\text { evaluation and analysis of its } \\
\text { influencing factors }\end{array}$ & $\begin{array}{c}\text { Environmental regulation; Agricultural } \\
\text { economic development level; Education } \\
\text { level; Agriculture training }\end{array}$ \\
\hline
\end{tabular}

\section{Interpretation of estimated results}

The estimated results of OLS, SLM, and SEM are summarized in Table 3. According to the values in Table 3, the R-squared value of each respectively is $0.6606,0.6683$ and 0.7468. The value of SEM, as well as SLM, is higher than that of OLS, which means that the assumption of the agricultural water environmental efficiency is independent of provinces in the least squares regression analysis. Thus the conclusion that the agricultural water environmental efficiency of thirty-one provinces in China is spatially related in section 3.3 is proved.

Comparing the LogL, AIC and SC values between SLM and SEM, it proves that SEM model is better than SLM model. This result shows that the efficiency of agricultural water environment in China is not only affected by the agricultural water environmental efficiency of neighboring provinces but also affected by the structural differences between regions. The differences include development level of the rural 
economy, agricultural structure change, rural industrialization, agricultural environmental infrastructure, environmental regulation and other factors not included in the model. Since the spatial error coefficient of SEM has passed the $1 \%$ significance level test, the existence of significant spatial dependence of agricultural water environmental efficiency in different provinces is tested.

Table 3. Regression results of the model

\begin{tabular}{|c|c|c|c|}
\hline Variable & $\begin{array}{c}\text { Ordinary least square } \\
\text { (OLS) }\end{array}$ & $\begin{array}{l}\text { Spatial lag model ( } \\
\text { SLM) }\end{array}$ & $\begin{array}{l}\text { spatial error model ( } \\
\text { SEM) }\end{array}$ \\
\hline CONSTANT & $\begin{array}{c}-0.7513 * * * \\
(-3.2943)\end{array}$ & $\begin{array}{c}-0.8283 * * * \\
(-4.0895)\end{array}$ & $\begin{array}{c}-0.8025 * * * \\
(-6.2615)\end{array}$ \\
\hline REDL & $\begin{array}{c}0.0336 \\
(1.2138)\end{array}$ & $\begin{array}{l}0.0401^{*} \\
(1.7602)\end{array}$ & $\begin{array}{c}0.0507 * * \\
(2.4834)\end{array}$ \\
\hline ASCP & $\begin{array}{c}0.5479 * * * \\
(4.3034)\end{array}$ & $\begin{array}{c}0.5835^{* * *} \\
(5.4939)\end{array}$ & $\begin{array}{c}0.6358^{* * *} \\
(7.8867)\end{array}$ \\
\hline ASCG & $\begin{array}{l}0.0078^{*} \\
(1.8012)\end{array}$ & $\begin{array}{l}0.0078^{* *} \\
(2.2238)\end{array}$ & $\begin{array}{c}0.0077 * * \\
(2.3521)\end{array}$ \\
\hline RI & $\begin{array}{c}-0.0420 \\
(-1.3450)\end{array}$ & $\begin{array}{l}-0.0454^{*} \\
(-1.7824)\end{array}$ & $\begin{array}{l}-0.0445^{*} \\
(-1.7995)\end{array}$ \\
\hline AEIL & $\begin{array}{c}0.0121 \\
(0.9185)\end{array}$ & $\begin{array}{c}0.0107 \\
(0.9816)\end{array}$ & $\begin{array}{c}0.0136 \\
(1.5101)\end{array}$ \\
\hline ERCOD & $\begin{array}{l}-0.1667 * * \\
(-2.1245)\end{array}$ & $\begin{array}{c}-0.1810 * * * \\
(-2.8122)\end{array}$ & $\begin{array}{c}-0.2225 * * * \\
(-4.3067)\end{array}$ \\
\hline ERNH & $\begin{array}{l}0.0833 * * \\
(2.1340)\end{array}$ & $\begin{array}{c}0.0938 * * * \\
(2.8570)\end{array}$ & $\begin{array}{c}0.1034 * * * \\
(4.4473)\end{array}$ \\
\hline$\rho$ & - & $\begin{array}{c}-0.1898 \\
(-0.8532)\end{array}$ & - \\
\hline$\lambda$ & - & - & $\begin{array}{c}-0.8208^{* * * *} \\
(-3.5484)\end{array}$ \\
\hline$R^{2}$ & 0.6606 & 0.6683 & 0.7468 \\
\hline $\log L$ & 24.8163 & 25.0475 & 27.0628 \\
\hline AIC & -29.6326 & -28.095 & -34.1256 \\
\hline $\mathrm{SC}$ & -15.2928 & -12.3211 & -19.7858 \\
\hline
\end{tabular}

Notes: ***, **, *, respectively, stands for the significant level of $1 \%, 5 \%$, and $10 \%$. The values below OLS are T-Statistics, and the values below SLM \& SEM are Z-Statistics

It can be seen from the above results that the efficiency of agricultural water environment influenced by the structural errors impact shows as follows:

(1) The positive estimated coefficient of rural economy development level (REDL) means that the improvement of rural economic development level can increase the efficiency of the agricultural water environment. With the improvement of rural economic development level, people's demand for water environment quality has also improved. Both farmers and government are paying more attention to the agricultural water environment, and this can improve the pollution problem thus can help to improve the efficiency of the agricultural water environment. Besides, agricultural environment-friendly production technology has been improved; and the resource 
consumption, as well as pollution generation, have been decreased. All these efforts promote the efficiency of the agricultural water environment.

(2) Agricultural structure change causes two kinds of influence on the efficiency of the agricultural water environment. On the one hand, the positive estimated coefficient of ASCP shows that the proportion of animal husbandry in agricultural output helps to the proportion of animal husbandry in agricultural output. The high added value of animal husbandry explains for that. On the other hand, the estimated coefficient of ASCG is also positive. It means that the proportion of grain crops in planting also counts. Rather stable fertilizing amount of grain crops and increasing fertilizing amount of cash crops can help to solve water environment problem because the fertilizer using does great harm to the water environment.

(3) The negative estimated coefficient of rural industrialization (RI) means that rural industrialization decreases the efficiency of the agricultural water environment. Firstly, the overdevelopment and overuse of resources in the process of rural industrialization pollute the rural water environment. Secondly, urban and rural industrial pollution transfer, unreasonable rural industrial distribution, as well as the extensive growth of the rural industry, also influence rural water environment efficiency.

(4) Positive agricultural environmental infrastructure level (AEIL) shows that the improvement of agricultural environmental infrastructure level has an impact on rural water environment efficiency, but with insignificant effect. Projects like irrigation and water conservancy, ecological engineering, water saving irrigation improve comprehensive agricultural production capacity and output level while decreasing pollution discharge and ecological destruction. However, problems like insufficient investment, unreasonable investment project and unmanned management after completion decrease the influence AEIL on rural water environment efficiency.

(5) The influence of environmental regulation on the efficiency of agricultural water environment can be divided into two parts. For the first part, the negative estimated coefficient of ERCOD shows that environmental regulation decreases the agricultural water environmental efficiency on the agricultural COD emission reduction side. The possible explanation is that the livestock and poultry breeding industry, which accounts for $90 \%$ of agricultural COD emission, is too dispersed for the specialized management system to be made. Moreover, the randomly caused pollution also adds to the difficulty. For the second part, if the estimated coefficient of ERCOD is positive, it means that the environmental regulation increases the agricultural water environmental efficiency on the agricultural ammonia and nitrogen emission side. This can be attributed to the fertilizer and pesticide management system since these two are the main sources of ammonia and nitrogen emission, and a series of such regulations have been released in China recently. Regulations like "Water Pollution Prevention and Control Law", "Pesticide Management Regulations" and "Regulations on the Protection of Basic Farmland" are among these effective measures.

\section{Conclusions and policy implications}

The strong disposable direction distance function was applied to measure the efficiency of agricultural water environment in 2013, and the spatial econometric model was further used to analyze the spatial effect of agricultural water environmental efficiency as well as its influencing factors. As a result, two main conclusions were drawn from the research. Firstly, agricultural water environmental efficiency in thirty- 
one provinces of China is spatially related. The two spatial distribution features are an unbalanced spatial distribution which presents gradually reduced distribution pattern from east to west and spatial aggregation where eastern coastal areas are mostly high with agricultural water environmental efficiency while the majority of mid-western regions stay in the low part. Secondly, regional structural differences among neighboring provinces also influence the agricultural water environmental efficiency apart from the mutual impact factor. Regional structural differences behave in many aspects such as economic development level of the rural area, agricultural structure changes, industrialization in the rural region, agricultural environmental infrastructure, environmental regulation, etc. These spatial influence factors perform their influences to agricultural water environmental efficiency in their way. For instance, the coordination of the above elements can be a benefit to the improvement of agricultural water environmental efficiency while the extensive rural industrial growth feature will do otherwise.

Based on the conclusions above, the following policy recommendations are drawn:(1) In treatment of agricultural water environment pollution, inter-regional cooperation in economic and environmental protection, spatial linkage of policy measures, cross-regional agricultural water ecological compensation fund and coordination of water environment management among different provinces (municipalities and autonomous regions) are all essential and should be taken into consideration. Specifically, the eastern area should set an example for and cooperate with the mid-western area in agricultural water environment management. For the midwestern area, the "scientific guidance, point to an area" principle should be followed and the detailed steps should be implemented gradually. In this process, the midwestern area should not just imitate from eastern area, adjustment of the policies are necessary when facing problems with specific characteristics of their own. (2) Here are some points every region should follow: Firstly, Improvement of their own economy level and cooperation with other parts should be important tasks, and integration of regional economy should be the target. Secondly, cleaner production and environmentally friendly technology should be advocated to optimize the agricultural structure. Thirdly, rural industrialization should be promoted to more intensive growth mode instead of the existing extensive growth mode. The fourth point suggests that investment in agricultural infrastructure should be increased to form a complete agricultural infrastructure system. Last but not least, policy tools like prevention and control measures, industrial adjustment, and financial support should be comprehensively applied as the inspiriting mechanism to help to improve the agricultural water environmental policy system.

The countries participating in the "Belt and Road" initiative, represented by China, mostly use agriculture as the main industry. There are problems in measuring and improving agricultural water environmental efficiency in these countries. Studying on the evaluation and influencing factors of China's agricultural water environmental efficiency has certain reference significance for the countries participating in the "Belt and Road" initiative.

This study only compares agricultural water environmental efficiency among the Chinese provinces. If the data includes other advanced countries, for instance, countries participating in the "Belt and Road" initiative, it may provide more information on the level of China's agricultural sector. Also, this research can be combined with 
Malmquist Productivity Index to investigate the technical efficiency change of China's agricultural sectors. All these remain avenues for future research.

Acknowledgements. We are grateful to the financial support provided by the National Social Science Foundation of China (No.12AZD108, No. 15CJL023) and the National Science Foundation of China (No. 71401052, No. 2016B03914).

\section{REFERENCES}

[1] Barnes, A. P., Moran, D., Topp, K. (2009): The scope for regulatory incentives to encourage increased efficiency of input use by farmers. - Journal of Environmental Management 90(2): 808-814.

[2] Chen, M. P., Chen, J. N., Lai, S. Y. (2006): Inventory analysis and spatial distribution of Chinese agricultural and rural pollution. - China Environmental Science 26(6): 751-755.

[3] Cole, M. A., Elliott, R. J. R. (2003): Do environmental regulations influence trade patterns? - Testing Old and New Trade Theories 26(8): 1163-1186.

[4] Fu, J. Y., Li, L. S. (2010): A case study on the environmental regulation, the factor endowment and the international competitiveness in industries. - Management World 10: 87-98.

[5] Fulginiti, L. E., Perrin, R. K. (1998): Agricultural productivity in developing countries. Agricultural Economics 19(1-2): 45-51.

[6] Gadanakis, Y., Bennett, R., Park, J. et al. (2015): Evaluating the sustainable intensification of arable farms. - Journal of Environmental Management 150: 288-298.

[7] Galanopoulos, K. (2004): Malmquist productivity index estimates for European agriculture in the 1990s. - Operational Research 4(1): 73-911.

[8] Han, H. B. (2013): Agricultural environmental technical efficiency and its determinants across provinces in China. - Research on Economics and Management 9: 61-68.

[9] Lai, S. Y., Du, P. F., Chen, J. N. (2004): Evaluation of non-point source pollution based on unit analysis. - Journal of Tsinghua University (Science and Technology) 44(9): 11841187.

[10] Li, G. C. (2014): The green productivity revolution of agriculture in China from 1978 to 2008. - China Economic Quarterly 13(2): 537-558.

[11] Li, G. C., Fan, L. X., Min, R. (2011): The coordination of agricultural development with environment and resource. - The Journal of Quantitative \& Technical Economics 10: 2136.

[12] Li, L., Tao, F. (2012): Selection of optimal environmental regulation intensity for Chinese manufacturing industry: Based on the green TFP perspective. - China Industrial Economics 5: 70-82.

[13] Li, S. X., Cheng, J. H., Wu, Q. S. (2008): Regional difference of the efficiency of water usage in China. - China Population, Resources and Environment 18(3): 215-220.

[14] Liang, L. T., Qu, F. T., Feng, S. Y. (2012): Agricultural technical efficiency measurement under the environmental constraints. - Journal of Natural Resources 27(9): 1580-1589.

[15] Min, R., Li, G. C. (2012): A study on growth and decomposition of China's grain TFP growth under environmental constraints: Empirical analysis based on provincial panel data and sequential Malmquist-Luenberger index. - Economic Review 5: 34-42.

[16] Monchuk, D. C., Chen, Z., Bonaparte, Y. (2010): Explaining production inefficiency in China's agriculture using data envelopment analysis and semi-parametric bootstrapping. - China Economic Review 21(2): 346-354.

[17] Nanere, M., Fraser, I., Quazi A, et al. (2007): Environmentally adjusted productivity measurement: An Australian case study. - Journal of Environmental Management 85(2): 350-362. 
[18] Pan, D., Ying, R. Y. (2013a): Evaluation of "Two-type Agriculture" development in China and its influencing factors. - China Population, Resources and Environment 23(6): 37-44.

[19] Pan, D., Ying, R. Y. (2013b): Regional disparity and dynamic distribution evolution of agricultural productivity growth in China under environmental pollution constraint. Forum on Science and Technology in China 5: 60-67.

[20] Picazo-Tadeo, A. J., Gomez-Limon, J. A., Reig-Martinez, E. (2011): Assessing farming eco-efficiency: A data envelopment analysis approach. - Journal of Environmental Management 92(4):1154-1164.

[21] Restuccia, D., Yang, D. T, Zhu, X. (2008): Agriculture and aggregate productivity: A quantitative cross-country analysis. - Journal of Monetary Economics 55(2): 234-250.

[22] Ruttan, V. W. (2002): Productivity growth in world agriculture: Sources and constraints. - Journal of Economic Perspective 16(4): 161-184.

[23] Sun, C. Z., Liu, Y. Y. (2009): Analysis of the spatial-temporal pattern of water resources utilization relative efficiency based on DEA-ESDA in China. - Resources Science 31(10): 1696-1703.

[24] Sun, C. Z., Xie, W., Jiang, N., Chen, L. X. (2010): The spatial-temporal difference of water resources utilization relative efficiency and influence factors in China. - Economic Geography 30(11): 1878-1884.

[25] Yang, J., Chen, Y. (2011): Empirical study on China's agricultural production growth under the binding of environment. - China Population, Resources and Environment 21(6): 153-157.

[26] Yang, Q., Liu, H. L. (2015): Regional disparity and influencing factors of agricultural water resources efficiency with the constraint of pollution. - The Journal of Quantitative \& Technical Economic 1: 114-128.

[27] Zhang, K., Feng, J. C. (2016): Agricultural environment efficiency and its dynamic evolution of China from the perspective of pollution's strong disposability. - China Population, Resources and Environment 26(1): 140-149. 